\title{
¿Los deberes o las prerrogativas del visir? Descubriendo a la familia de Rej-mi-ra
}

\author{
Mara Castillo Mallén
}

En este artículo se reflexiona sobre la posición que consiguió la familia del visir Rejmira y sus consecuencias en la política del Reino Nuevo. La autora inicia con él un estudio de los textos relacionados con el cargo de visir enfocándolos como elementos ideológicos al servicio de la citada familia.

\section{Duties or privileges of the vizir? Discovering the family of Rekhmira}

In this article, the author reflects about the position obtained by the family of the Vizier Rekhmira and the political implications in the Egyptian New Kingdom. At the same time, she starts the study of texts related to the Vizier as ideological elements in the service of that family.

KEY wORDs: Thebes, 18th Dynasty, Rekhmire, Vizierate, Ethnicity

$\mathrm{E}$ planteamiento inicial de mi investigación se centraba en el análisis de los textos relacionados con el visirato y su permanencia en el seno de una sola familia desde que ésta asume responsabilidades públicas. Me proponía comprender el protagonismo de los textos en el programa desarrollado tanto por Rejmira, como por sus antecesores, para lo cual estimé oportuno establecer una prosopografía capaz de sistematizar en qué punto nos hallamos con relación al conocimiento de esta dinastía nobiliaria y a su inserción en el sistema nobiliario que rigió durante el Reino Nuevo los destino de Egipto desde Tebas.
En la publicación de la tumba de Rejmira ${ }^{1}$ (TT 100), Norman y Nina de G. Davies apenas hacen referencias a los ascendientes del propietario, salvo para señalar las escenas en las cuales están representados ${ }^{2}$, resaltar la relevancia de tío y abuelo en la distribución de imágenes y aludir al hijo fallecido ${ }^{3}$ de Useramón como el designado para heredar el visirato $^{4}$. Posteriormente, en la monografía de Guido P.F. van den Boorn ${ }^{5}$, vemos un intento de ordenar el árbol genealógico del noble, aunque el autor otorga a su planteamiento la categoría de hipótesis y trabaja sobre la base

* El presente trabajo forma parte de mi proyecto de investigación financiado por el Ministerio de Ciencia y Tecnología dentro de su programa de Becas Postdoctorales. y llevado a cabo en el Seminario de Egiptología de la Universidad de Basilea.

1. Davies y Davies, 1944.

2. Davies y Davies, 1943: pl. IX y X.

3. Sa-Menjej, representado en la Estela Uriage (Museo de Grenoble) honrando a su padre y a su abuelo. Hornung (1965: 75-76) modificó la grafía del nombre y aludió a Sa-Menjet aunque sin duda se trata del mismo personaje.

4. La Estela Uriage parece ser un elemento definitivo por el destacado papel que juega el hijo como oferente de los dos visires anteriores, su padre y su abuelo Sin embargo, no encontramos en su titulatura evidencias que permitan afirmar su destino, a pesar de la insistencia con que la investigación ha resaltado este hecho.

5. van der Boorn, 1988.

Fecha de recepción: 31 de enero de 2007

Fecha de admisión: 25 de junio de 2007 


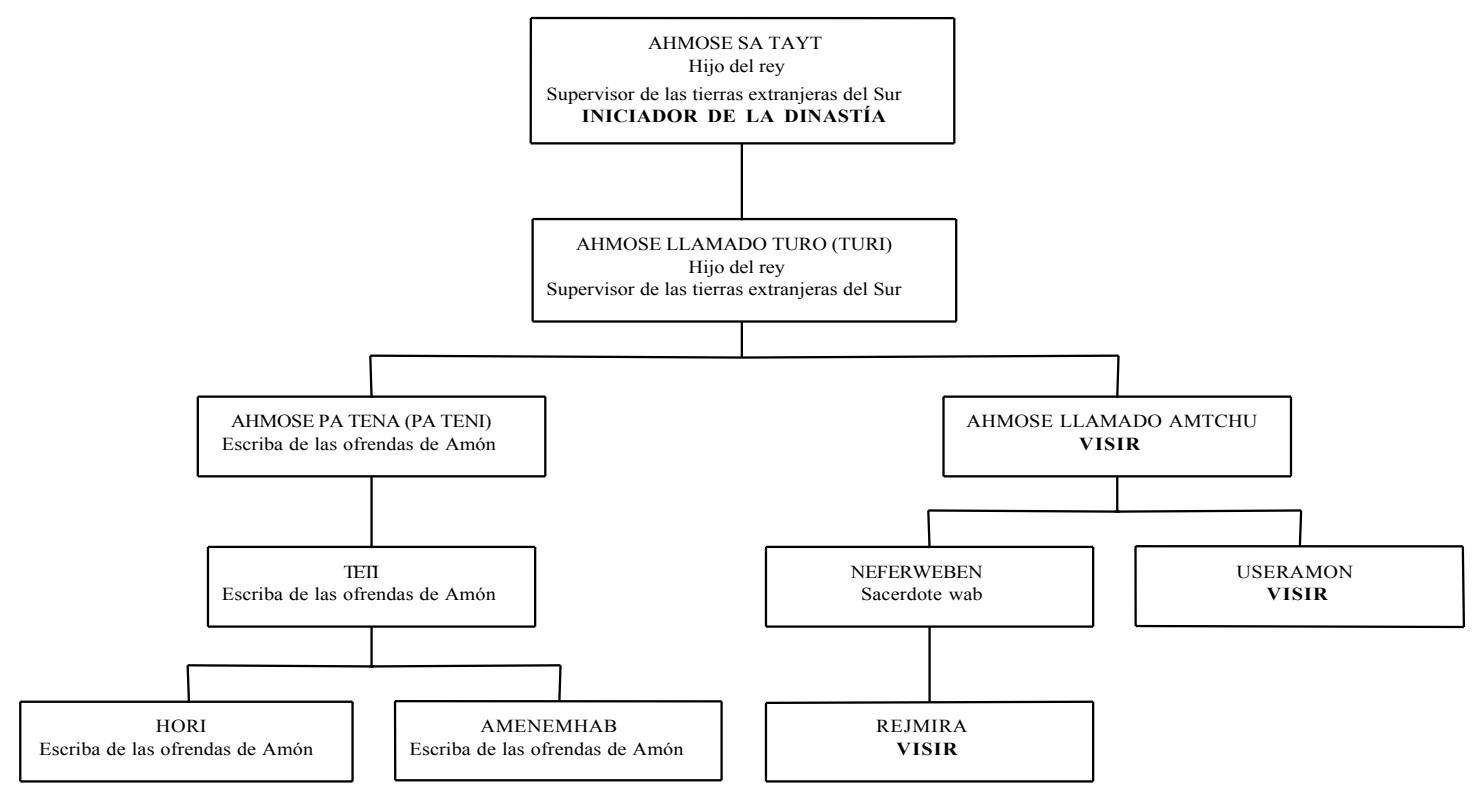

Organigrama $n^{\circ}$ 1: Genealogía Rejmira

de supuestos, constreñido por el horizonte documentario que se le presentaba. En realidad, con la información de que disponemos en la actualidad, estamos lejos de poder establecer el linaje completo de Rejmira y es tanto más complicado cuanto más avanzamos en la extensión del linaje a través del tiempo. Para los intereses del trabajo, fijaremos un paradigma prosopográfico que incida más en las responsabilidades de gobierno adquiridas por el clan, consolidado de este modo más como un Grupo de Poder que como una familia. hasta su culminación durante el mandato de Rejmira, que en el árbol genealógico. Así pues, podemos aventurar que el organigrama $n^{0} 1$ expone la situación de forma clara: sólo una generación separa al iniciador -hasta donde conocemos en la actualidad-de la dinastía del control que ejerció la dinastía sobre los tres sectores más importantes del poder estatal: a) Cargos administrativos relacionados con los recursos económicos adscritos a la divinidad por excelencia del Reino Nuevo, Amón;

b) control político, militar y económico de Nubia, con todo lo que representaba;

c) máxima representación de gobierno, es decir, el visirato.

Los tres pilares del poder a los que acabamos de referirnos se transmitieron en el Egipto del Reino Nuevo dentro de la parentela durante al menos cuatro generaciones y en un momento dado, como queda de manifiesto en el organigrama $\mathrm{n}^{\mathrm{o}} 2$, Ahmose Sa Tayt consiguió ver a su hijo Ahmose, llamado Turo, heredando el cargo de Hijo Real de $\mathrm{Kush}^{6}$ al mismo tiempo que sus nietos ocupaban respectivamente el visirato y el gobierno administrativo del templo de Amón mediante el cargo de

6. Uso el título como convención a pesar de que, no es hasta Amenhotep III cuando el gobierno del territorio pasar a ser denominado con la titulatura completa. 
AHMOSE SA TAYT

Cabeza grupo familiar

Cargos en Nubia

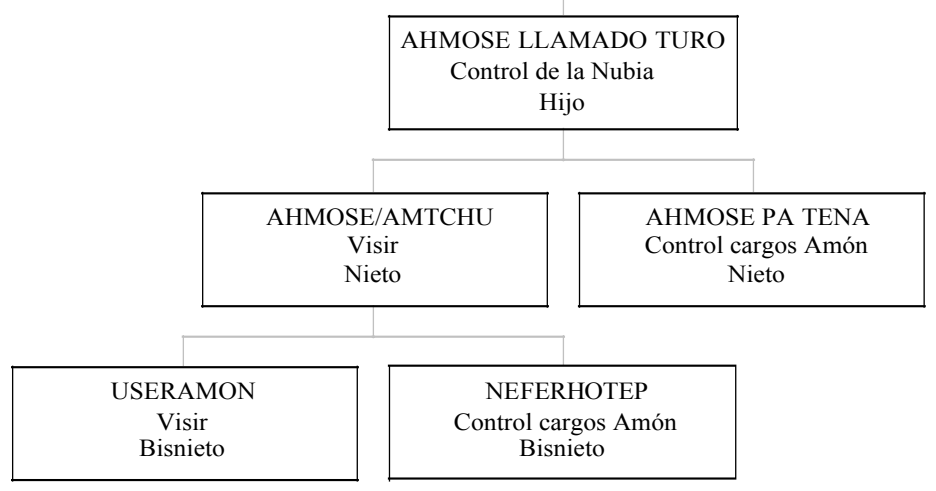

Organigrama $n^{\circ}$ 2: Sincronía de cargos

segundos profetas ${ }^{7}$. Estamos ante la familia que diseñó el Reino Nuevo tal y como lo entendemos, ya que no es posible vislumbrar un horizonte que permitiera a los reyezuelos tebanos alcanzar el sueño de gobernar en todo el territorio, sin el soporte militar, político y económico, no sólo de este linaje en cuestión, sino del grupo nobiliario al cual pertenecía y representaba.

Conviene tener presente que la coincidencia en derredor de Tebas de un poderoso clan nobiliario con procedencia tanto de El-Kab como de Armant, se halla en la base del empeño "unificador" del cual es deudor cualquier monarca tebano del Segundo Período Intermedio ${ }^{8}$ La visión clásica de una dinastía reinante que aglutina diversas facciones aristocráticas, lidera el país hacia una gloriosa victoria, y una vez conseguida ésta, reorganiza el territorio, política y administrativamente, es deudora de una concepción del estado egipcio que convendría ir revisando.
Esta noción regicéntrica es la apuesta de van den Boorn al considerar la sucesión visiral en el seno de la familia de Rejmira como el fruto de una planificación del faraón Ahmose $^{9}$ derivada de su apuesta por la reorganización territorial tras su victoria $\mathrm{y}$ la pacificación del país, tomada como paradigma indiscutido por la investigación. Por tanto, la ascensión al poder del primer visir, Ahmose-Amtchu, sincronizaba con el gobierno de Ahmose-Turo en Nubia, ya que el monarca así lo disponía con el fin de asegurar-siempre según la propuesta de van den Boorn $^{10}$ - estabilidad al país; al parecer, ésta sólo podía lograrse confiando en la familia en cuestión.

No obstante lo anterior, si analizamos la circunstancia desde un enfoque metodológico distinto, surge la posibilidad de plantearnos algunas interesantes cuestiones:

- ¿Ahmose era capaz de prever la sucesión de los cargos políticos en Egipto más allá de su

7. Davies, 1943: 101.

8. Vernus, 1982: 135.

9. van der Boorn, 1988: 370.

10. van der Boorn, 1988: 370. 
propia muerte?, ¿qué papel jugarían entonces sus sucesores? ¿no eran suficientemente competentes para aglutinar a su alrededor las oportunas lealtades y se vieron obligados a ser feudatarios del diseño ahmósida?; ¿Es razonable suponer que un monarca reorganice el estado en base a un plan diseñado al margen de los intereses de sus descendientes y dejando a su estirpe al albur de una facción aristocrática a la cual ha entregado de facto las llaves del reino materializadas por los más altos cargos políticos posibles?

- ¿Qué hacía a la familia de Ahmose Sa Tayt merecedora de un privilegio y una responsabilidad de este calibre, en un momento tan delicado para Egipto?

- ¿Parece adecuado reconocer que, tras una guerra civil ${ }^{11}$ que enfrentó intereses nobiliarioterritoriales bien contrapuestos, la solución, lejos de perseguir algún tipo de concordia al estilo shema tawy en la noción de Goedicke ${ }^{12}$, hiciera descansar la victoria en un solo grupo y se pueda entender el hecho como una pacificación?

Considero más conveniente desplazar el enfoque de la situación desde la realeza hasta la nobleza, y dentro de la misma, acudir en busca de respuestas a la preeminencia que pudo haber obtenido esta familia frente a sus pares. Así mismo, conviene dirigir la mirada a las ya mencionadas vinculaciones con El-Kab ${ }^{13}$, cuyas implicaciones apenas si están comenzando a aflorar ${ }^{14}$, antes que a un altruismo "patriótico" protagonizado por las elites territoriales en favor del "bien común".

Cualquier intento de analizar los factores desencadenantes de una ascensión de similar calibre se enfrenta a un hecho que resulta cuanto menos difícil de aceptar desde un enfoque metodológico tradicionalista. Si nos atenemos a la frecuencia con que se repite el nombre del faraón iniciador de la dinastía XVIII entre los personajes que estudiamos y observamos sus epítetos, parece razonable admitir que, con Ahmose Sa Tayt estamos ante el primero de su estirpe, una estirpe extranjera, naturalizado egipcio.

\section{NOMBRES, ORÍGENES Y ETNICIDAD}

La invariable línea ahmósida de la familia y su decidida apuesta por la conservación de epítetos, que permanecen hasta el abuelo de Rejmira, invita a reflexionar acerca de los orígenes territoriales del clan y permite aventurar que, antes de su asentamiento definitivo en una zona dentro de las fronteras egipcias ignorada hasta el momento, la estirpe del visir Rejmira ya arrastraba tras de si el protagonismo de una historia fuera del territorio egipcio y en esa hipótesis vamos a desarrollar nuestro trabajo.

11. Es una guerra civil lo que hubo en Egipto durante el Segundo Período Intermedio. A despecho de cualquier otra lectura, el enfrentamiento entre distintos territorios que conforman un país o estado recibe la denominación de guerra civil independientemente de que elementos extranjeros intervengan en la misma. Teti, hijo de Pepy era tan egipcio o tan poco egipcio como Ahmose hijo de Abana y parece claro que el primero optó claramente por un bando bien distinto del segundo. Podríamos afirmar, en un lenguaje moderno, que ambos "tenían visiones distintas de cómo debía ser su país” y alguna de ellas no era compatible con el intento hegemónico tebano.

12. Goedicke, 1985, 307-324.

13. La Nejeb egipcia. Habachi, 1959: 54 apostaba por un origen tebano de la familia, al menos desde Turo, en virtud de sus tumbas no siendo contradictorio con la propuesta que defiendo. No obstante el asunto no debe considerarse cerrado sino a la espera de documentación que confirme o desmonte tal afirmación.

14. De las relaciones entre los títulos "Hijo Real" "Hijo Real de Nejeb" e "Hijo Real de Amón” y su incardinación en la dinámica del magma político egipcio desde el Segundo Período Intermedio hasta al menos la primera mitad de la dinastía XVIII, no es posible dejar constancia en el corto espacio de este congreso. 
En cuanto al lugar de instalación de la familia en Egipto, la documentación surgida hasta el momento otorga igual verosimilitud a la zona fronteriza con Nubia, por los cargos relacionados con esta región que portan los ascendientes, al área del nomo tebano, por la indudable vinculación con Tebas y, desde luego, no se puede descartar de la opción de El-Kab ${ }^{15}$.

Hasta la llegada al poder de los hermanos Ahmose Pa Tchena y Ahmose, llamado Amtchu, bajo la atenta supervisión de su padre, la estructura de los nombres permaneció inalterable en la familia: asociados al faraón iniciador del Reino Nuevo y apoyando su factor diferenciador en los cognomina.

Así Sa Tayit ${ }^{16}$-filiación materna ${ }^{17}$ del personaje inaugural de la línea-, disfruta de muy limitadas entradas en Ranke ${ }^{18}$ y éstas conducen de nuevo a la propia familia y, nuevamente a Nejeb ${ }^{19}$ de la mano de un escriba ${ }^{20}$ que trabajó bajo la responsabilidad de Pa-Heri. Sin embargo, de los tres sucesores que comparten nombre ${ }^{21}$ conviene destacar al abuelo de Rejmira, Ahmose llamado Amtchu, probablemente el portador del epíteto más sorprendente y con una identificación más clara. Sus entradas son bien restringidas en el ya mencionado Ranke ${ }^{22}$ y pese a ello encontramos su rastro ya durante el Primer Período Intermedio-inicios del Reino Medio, en la necrópolis de Beni Hasan ${ }^{23}$ acompañando la famosa inscripción de Abishai en la tumba del nomarca Jnmujotep (II).

Thomas Schneider ${ }^{24}$, en su trabajo acerca de los nombres semitas en Egipto, establece una relación semántica y natural entre el cognomen que nos ocupa, Amtchu y el nombre Amós, correspondiente al profeta hebreo y muy posterior en el tiempo. Según su planteamiento, el primero no sería más que la forma egiptianizada del segundo, un nombre propio común entre semitas asentados en el territorio egipcio desde antiguo, razón por la cual el origen étnico de la familia estaría fuera de toda duda.

Un dato que añadir es el nombre de su esposa: Ta-Amtchu. De su estudio se deriva un claro vector territorial, centrado en Nejeb. Profundizando en el origen encontramos paralelos en una lista de sirvientas semitas que Ahmose hijo Abana $^{25}$ obtuvo como premio por sus actividades bélicas. No obstante, la partícula ta al principio del nombre, apunta al menos en dos sentidos: el

15. Al igual que en la nota anterior, nos extenderíamos excesivamente justificando la opción de El-Kab. Baste afirmar Ahmose Pa Nejbet y Jaemwaset son dos hermanos de Ahmose Sa Tayt enterrados juntos en la Tumba n 2 de El-Kab.

16. Escrito con Gardiner M18.

17. Me parece más oportuno optar por la filiación materna que por la adscripción religiosa. Las características de esta divinidad y el período en que nos movemos, parece autorizar esta licencia. Habachi, 1959: 54 en cambio considera que se trata del fundador de la dinastía y padre de Ahmose Sa Tayit.

18. Gauthier, 1917: 183.

19. Urk. IV, 135: 17.

20. Lleva el mismo nombre, aunque con M17 replicada. La escritura de los nombres es quizá el ámbito donde más libertades se tomaban los escribas y es muy dependiente de gustos personales, asimilación de formas que obtienen éxito entre la elite y otros muchos factores difíciles de aprehender.

21. Cognomina y epítetos están siendo estudiados en este momento por lo que únicamente es posible avanzar aquí algunas reflexiones.

22. Ranke, 1935: 59, Urk. IV, 1119: 2.

23. Newberry, 1893: 30.

24. Schneider, 1992: 71.

25. Urk. IV, 11: 9. 
primero establecería una relación esposo-esposa en la cual, a través del apelativo, se reconocería algún tipo de supremacía dentro del nivel social ${ }^{26}$ $\mathrm{y}$ el segundo, siguiendo antiguas formulaciones actualmente en desuso, pero interesantes ante la disyuntiva que enfrentamos, tendería a relacionar a la mujer con su propio vínculo familiar estableciendo su filiación paterna. En ambos casos, sorprende la utilización para tales fines del referente étnico "Amtchu" y no de la marca egipcia "Ahmose", lo cual nos obliga a concluir que, por encima de cualquier otra consideración, se pretendía destacar el origen de ambas familias.

Lejos de metamorfosearse con el paisaje egiptianizante, actitud habitual en otros linajes foráneos cuando accedían a las escalas superiores del $\operatorname{poder}^{27}$, la afirmación de su excepcionalidad formaba parte del devenir histórico de la comunidad étnica y cultural a la cual pertenecía la estirpe que estudiamos y, lo que es más importante, ello no les impedía alcanzar la más alta responsabilidad del estado y dedicar su inteligencia y esfuerzo a la perpetuación del modelo egipcio y, en este época por extensión, tebano.

De todos modos, el proceso debió de ir desarrollándose paulatinamente. No podemos caer en la tentación de considerar que cualquier grupo de inmigrantes con autorización para asentarse en Egipto conseguiría escalar socialmente en un recorrido temporal breve. En consecuencia, y aceptando las propuestas anteriores, podríamos la familia y asumir como hipótesis plausible que existiera en el seno de la misma una tendencia a emparentar con otras de similares características étnico-culturales. Evidentemente el trabajo que resta para determinar con exactitud no sólo la ascendencia Rejmira, sino también las conexiones matrimoniales que fueron fraguándose como alianzas desde los tiempos de Ahmose Sa Tayit, es complejo e inmenso y no creo posible concluirlo en breve plazo.

Para finalizar la primera parte de esta exposición, quisiera remarcar un aspecto puramente estético que se relaciona con la percepción que poseía la familia de sí misma, bien definida por el modo de aplicar las variables de escritura a las que hemos aludido. La forma de Amtchu suele aparecer con el signo Gardiner T14, a fin de remarcar la condición de servil o vencido del portador $^{28}$, pero en esta ocasión se evitó. Los Ahmose/ Amtchu ya no pueden ser incluidos en listas de vencidos y el signo se excluye intencionadamente.

\section{VISIRATO, TEXTOS IDEALES Y TEXTOS NORMATIVOS}

El número y organización de los visires conocidos hasta el momento no fundamenta en mi opinión la creencia, generalmente extendida, de dos titulares a los cuales se encomendara la tarea de control sobre norte y sur del país. Para apoyar las dudas que surgen en relación a este desdoblamiento del cargo, uno de los argumentos más

26. A. Loprieno en conversación personal, me hizo notar la posibilidad de que el nombre de la abuela de Rejmira no hubiera sido en origen el que usa en la documentación a nuestra disposición, siempre como la esposa del visir, y que éste se debiera precisamente al vínculo matrimonial. En términos socio-políticos esta hipótesis nos conduciría directamente a las relaciones clientelares entre ambas familias y a la aceptación por parte de la primera de su relación de dependencia con la segunda, sustituyendo el nombre de la mujer por una afirmación bien concreta "la (que es de, que pertenece a) Am-tchu".

27. El caso nubio es una claro ejemplo de la diferencia con que unos y otros grupos culturales penetran el tejido social egipcio.

28. Así es incluso en el calificativo de asiático, del cual podría derivar el apelativo al que aludimos, y en una buena cantidad de las referencia a pueblos o tierras extranjeras (nubios, libios, etc.). 
significativos es la abundante documentación que se conserva para los denominados visires del sur. Por el contrario, son relativamente escasos los documentos que aportan aquellos otros nobles relacionados con el mismo cometido en el Delta, lo cual reforzaría la hipótesis de que sólo en casos excepcionales y por motivos de alianzas estratégicas y/o clientelares, encontraríamos una bicefalia en tal responsabilidad, al menos durante el Reino Nuevo. Sin embargo, hay que hacer esta afirmación con cautela, pues los arqueólogos han primado el área tebana y sólo recientemente el Delta ha comenzado a atraer su atención ante la enorme cantidad de información que aún custodia; no obstante, la figura del visir va unida a toda una serie de responsabilidades que le obligaban a viajar por el país, siendo posible rastrear la documentación material tanto en las necrópolis septentrionales como en cualquiera de las múltiples ocasiones propicias ${ }^{29}$ para dedicar una estatua, inscribir una estela, etc.; como tal cosa no ha sucedido en relación a los visires del norte, cabe suponer que no es la ausencia de excavaciones lo que nos mantiene ignorantes de su cantidad y personalidad y quizá debamos admitir sencillamente que no se descubre información porque no hay testimonio que revelar.

De cualquier modo, no existe a mi juicio, un argumento sólido que respalde la necesidad de un desdoblamiento del poder y durante el período de Rejmira parece bastante difícil, por las razones que se aducirán más adelante. Una visión romántica y excesivamente centrada en el papel de la monarquía es responsable de contradicciones que son aceptadas con naturalidad pasando sobre ellas sin rozarlas. Un ejemplo es la posible ubicación del aparato real, la institución y sus mecanismos. Pese a contar con pruebas suficientes para aceptar la poca presencia del faraón en Tebas y su paulatino pero firme exilio al norte, un sector de la ciencia actúa como si ésto no hubiera ocurrido, aceptando en el plano teórico el distanciamiento geográfico pero manteniendo una metodología de trabajo que desestima ese mismo factor como elemento de análisis. Insertando el mismo vector territorial en el estudio del visirato, no hay prueba de variación alguna desde comienzos de la dinastía XVIII hasta época tutmósida, que autorice un cambio de la magnitud que supondría la bicefalia en la cúpula del poder político. Por otra parte, el férreo control que desde ese mismo período $-\mathrm{y}$ aún anteriormente- ejerció sobre el puesto la familia de Rejmira, justifica las dudas que surgen. Bien podría ocurrir que el visir contara con un delegado o colaborador en el norte, que atendiera los asuntos de la residencia y transmitiera las novedades, un aspecto que ya fue capaz de vislumbrar Dairaines a principios de siglo:

Devant l'importance grandissante des fonctions de vizir, et aussi dans un but de décentralisation le pharaon d'adjoignit dès le début de la XVIIIe dynastie un second vizir. L'un gouverna le Nord de l'Egypte avec siège à Héliopolis, l'autre le Sud à partir d'Assiout mais seul le vizir du Sud, gouverneur de Thèbes conserva le privilège de remplacer le pharaon en son absence ${ }^{30}$.

Sólo el visir de Tebas es el visir, lo cual corrobora un repaso a las titulaturas que emplean los del Sur frente a los del Norte, inclinando la balanza visiblemente hacia los primeros en función de la acumulación de cargos y cometidos en las dos tierras que no son, ni mucho menos paralelos a los de sus homólogos, pues mientras aquellos reconocidos como propiamente sureños y protegidos por el sistema tebano acaparan ocupaciones en todo el país, el resto circunscribe su actuación al ámbito septentrional.

29. Como así resulta en Kush y otras localizaciones en principio menos accesibles.

30. Dairaines, 1933: 39. 
Retomando al emblemático Rejmira, cuya carrera se desempeñó en un período para el cual la investigación es partidaria del doble visirato ${ }^{31}$, encontraremos que la relación de títulos que acumula es francamente apabullante. Sin embargo, más allá de la impresión que nos pueda causar su cursus honorum, llama aún más la atención su comparación con el de Parajotep ${ }^{32}$, visir durante el reinado Ramses II, que muestra bien a las claras en su titulatura la falta de autoridad sobre la Cabeza del Sur ${ }^{33}$, su ámbito de influencia se circunscribe al Bajo Egipto.

Pierre Grandet admite una bicefalia que da por concluida durante el reinado de Ramsés III $^{34}$, sin explicación que justifique la medida y menos suponga el fin del departamento norteño precisamente en el momento en que la realeza estaba definitivamente asentada en la zona. De haberse producido una reunificación del cargo cabría esperar que fuera el tebano quien se diluyera en favor del más racional intento de que la oficina del visir y el visir mismo estuvieran siquiera próximos a su teórico jefe supremo, el faraón:

Dans la forme traditionnelle de l'administration égyptienne il existait deux vizirs, l'un pour la Basse-Égypte, dont le siège était en principe à Memphis (mais sans doute aussi parfois à PiRamsès) ${ }^{35}$, el l'autre pour la Haute-Égypte, qui résidait à Thèbes. Sous Ramsès III, ce mode d'organisation «bicéphale» fut pratiqué jusqu'en l'an 29, où To, vizir de Haute-Égypte, vit ses compétences étendues à la Basse-Égypte. Si nous ignorions, du règne de Siptah à cette date, jusqu'à l'identité des personnages qui furent vizirs du nord, ceux du sud sont en revanche mieux connus

Una vez más se percibe ${ }^{36}$ la esencia del poder al observar que semejante final tiene como consecuencia que el visir del Alto Egipto viera extenderse sus competencias al Bajo Egipto en franca contradicción con la época, si somos rigurosos.

En la actualidad, las únicas fuentes textuales directas para aproximarnos tanto a la problemática anterior como a la función específica del visir, se encuentra en los textos de La Instalación del visir y Los Deberes del Visir, y ninguno de ellos es compatible con la propuesta de reparto territorial, lo cual no significa, como ya apuntábamos con anterioridad, que el cargo no pudiera ser ejercido por más de una persona en el mismo espacio temporal, pero siempre que ocurriera habría que conceder una jerarquización, un principal y un subordinado, y el superior estaría sin duda en el centro neurálgico del poder, Tebas. También debe integrarse en la ecuación que se propone, una realidad estructural de suma importancia, a saber, el cargo no hace al personaje sino al contrario, Rejmira era visir porque tenía poder, pero sin el cargo, su ascendencia política, social y económica no variaba un ápice, otros investidos, tenían poder porque eran visires. El argumento de la doble titularidad es, por tanto, uno de los principales enemigos de los textos protocolizados que nos ha sido legados y su

31. Adjudicando Thutmosis III la regulación del mismo.

32. De Meulenaere, 1966: 223-232.

33. De Meulenaere, 1966: 225.

34. Grandet, 1993: 1.

35. En el propio texto ya aparece uno de los principales escollos que debe afrontar la división del cargo y es la imposibilidad de armonizar la presencia de un visir en Tebas y otro en Menfis ambos distanciados por tanto del lugar en que se asienta la residencia del faraón. La falta de comunicación entre un centro de poder representado por el visir y otro bajo responsabilidad real será tratada más adelante al analizar los textos normativos del visirato.

36. Tomando en consideración la hipótesis del doble visirato y simplemente como ejemplificación de que al fin, incluso los partidarios de la misma concluyen aceptando que su desaparición no hace más que poner de manifiesto en que segmento territorial se asentaba el poder. 
aceptación debería en todo caso ir acompañada de la admisión, por parte de los especialistas, de la función meramente ideal que ambos tratados destilan; sin embargo las dos propuestas conviven en la actualidad. La opción de este trabajo se basa en una transformación del paradigma dejando abierto el debate acerca del título pero defendiendo la evanescencia de los dos textos cardinales.

\section{Apuntes SObre "Los Deberes del VisiR"}

La intención del apartado que se desarrolla a continuación no es tan ambiciosa como para tratar de analizar pormenorizadamente el texto en cuestión, aunque sí es su propósito reflexionar acerca de algunos de sus pasajes, con el fin de ilustrar con mayor claridad la postura que se arguye a modo de cierre para el debate acerca de la funcionalidad de un doble visirato y sus posibilidades de certidumbre.

Lo más sobresaliente de este tratado, apenas estudiado aunque profusamente citado, es el hecho de que un compendio de tal envergadura sólo aparezca en un número limitado de tumbas -tebanas por más señas- estando al menos tres de ellas unidas por fuertes lazos familiares ${ }^{37}$, que constituyen una suerte de dinastía visiral. La permanencia de la familia en el cargo, cuyo primer propietario fue considerado en el Reino Nuevo el modelo de visir ${ }^{38}$, es una de las pruebas más eficaces del paradigma que se viene defendiendo en el presente trabajo. Por razones que desconocemos en la actualidad pero sin duda beneficiosas para los intereses del entorno familiar, el padre de Rejmira permaneció como sacerdote $w a b$, sin que se le conozcan más cargos públicos, aunque desde luego está muy lejos de jugar el papel insignificante que le otorga Davies en su monografia:

Nefer-Weben, though a son of the vizier Amotu and brother to his successor Amen-wosre, was himself probably only a humble priest of Amun at the time of his own son's birth ${ }^{39}$.

Posteriormente $^{40}$ recondujo su juicio y apoyándose en documentos publicados por A.M. Blackman, D. Dunhman y J. Capart ${ }^{41}$, avanzó la posibilidad de que también el padre alcanzara el visirato, circunstancia que habría sido omitida en la tumba del hijo debido a las implicaciones políticas de su nombramiento bajo Hatshepsut. Justifica sus afirmaciones aludiendo a un enfrentamiento del jefe de familia (Amtchu) con la monarca. Al intentar frenar las extremas pretensiones de la dama, fue cesado a favor de su hijo, siendo reinstaurado por el sucesor, que también se ocupó de User nombrándolo asistente del pa$\mathrm{dre}^{42}$.

Una vez más, la incapacidad de presentar una visión de conjunto y la ignorancia del funcionamiento que se corresponde con el régimen de familia extensa, perjudicó al autor en su valoración, por lo demás romántica en exceso como se deriva del siguiente párrafo:

But when he first looked into the eyes of the newborn child and named him Rekh-mi-Rea ("Wise-as-God), he set a destiny which the boy,

37. La última inscripción del texto corresponde a la tumba Paser (TT106). Hasta el momento no se ha podido hallar conexión entre los propietarios al margen del cargo común; no obstante el estudio del entorno de Paser resulta muy esperanzador a este respecto.

38. Davies, 1943: 17.

39. Davies, 1943: 3.

40. Davies, 1943: 101.

41. Blackman, 1917; Dunhman, 1929; Capart, 1934: 114.

42. Resolviendo de este modo la co-regencia no explicada. 
strange to say, accepted and in some measure fulfilled $^{43}$.

Sin necesidad de oráculos, el padre de Rejmira, como anteriormente su propio padre con él y con su hermano, era muy conscientes de que el destino del niño no pasaría por quemarse al sol de las canteras, sino que le permitiría lucir el lino blanco reservado a los más privilegiados. En la tumba de este heredero singular, las figuras de abuelo y tío ocupan un lugar preeminente tras los hijos que ejercen el ritual de las ofrendas, $y$ el motivo es sin duda la correspondencia profesional; la línea de poder pasó del tío al sobrino soslayando al hijo y al hermano, sin que ello deba entenderse como menosprecio o falta de capacidad. Aún en la actualidad, algunas monarquías de países orientales utilizan la misma fórmula, es el hermano y no el hijo del monarca reinante, el heredero oficial, lo cual no significa que en un momento dado y en virtud de las necesidades estratégicas familiares, pudieran invertirse los tér$\operatorname{minos}^{44}$.

La compleja sepultura del noble se regocija en plasmar una situación social que, sin dañar el protocolo, es capaz de transmitir con exactitud la posición destacada de la familia en los asuntos de Estado y también el elevado concepto que tienen de sí mismos y de la oligarquía que integran, la tebana. Las afirmaciones de los nobles que se acercan a saludar a Rejmira ponen de manifiesto un modelo de gobierno absolutamente compa- en presencia del rey, dirigen a éste las palabras siguientes:

El gobernador $(h q 3)$ bueno en monumentos Men-jeper-ra, que confirma cada oficio y construye templos con regulaciones y principios rectos de todo tipo....él está seguro en su lugar ${ }^{45}$ y los hijos de los nobles en los de sus padres. ¡Ojala pueda repetir lo propio por millones de años, mientras permanezca seguro en el trono de Horus ${ }^{46}$.

No cabe mayor sutileza ni explicación más clara de cuál es el comportamiento que se esperaba del faraón, y de qué dependía exactamente la celebración de jubileos reales.

Por otra parte, las continuas y rotundas referencias al poder del propietario confundieron a Davies, hasta el punto de verse en la necesidad de apostillar continuamente en un fútil intento por hacer concordar el texto con el modelo de Egipto habitual durante la época en que el estudioso se dedicó a las tumbas tebanas. Una de las más notables, por su ingenuidad, es la que incorporó al texto que describe una escena de corte de la que fue expugnada la figura del visir, aunque se conservaba el mensaje y también una extraña vinculación entre los cartuchos reales y el nombre del propietario de la tumba, objeto del problema, y resuelto por Davies del siguiente modo:

Perhaps the construction is less a hall than a baldachin within it supported on six columns. The latter take form of stylized palms, such as are often adopted for indoor use. The shafts are adorned halfway down with cartouches of the king, "beloved of Maaet" (goddess of justice), and the name of Rekh-mi-Rea... ${ }^{47}$.

43. Davies, 1943: 3.

44. Especialmente las monarquías de Marruecos, Jordania, Arabia Saudí, Emiratos Árabes Unidos, por citar algunas, mantienen el método al que me refiero y todas ellas se basan en relaciones familiares explicables por el modelo de familia extensa.

45. zt puede ser traducido tanto por trono, como asiento o lugar, las tres acepciones se ajustan al significado de la oración y lo sustancial es mantener la traducción elegida tanto para el inicio de la frase -relacionada con el faraón-como para el final-que se refiere a los nobles.

46. Davies, 1943: 17. La cursiva es mía. 
El autor se vio forzado a incluir una nota a pie de página justificándolo:

This is not arrogance. The name of the vizier faces that of the king above it, as the cartouches of the later are made to face the name of Maaet, as if in homage ${ }^{48}$.

Los prejuicios en cuanto a las afirmaciones del noble son una realidad actual que se estrella con la brutal sinceridad de un hombre en la cima de su carrera, adornado de un fino sentido del humor, que le lleva a plasmar en su tumba testimonios contradictorios ${ }^{49}$ de una misma situación, correspondiendo a los historiadores desbrozar la interpretación alejando de nuestros trabajos el decorum. La discrepancia es tanto más aparente cuanto la ciencia da por válidos registros que se inscriben en un mundo ideal y persiste en analizar la documentación textual e iconográfica con raseros diferentes, en función de los intereses que nos animen. En el caso de las tumbas, esta circunstancia es muy común, ya que cualquier desviación del modelo establecido se remite al mundo de lo etéreo, sin relación con la pragmática vida terrenal, aunque se mantenga la función de escaparate social vinculada inseparablemente al sepulcro, creando una paradoja aún no resuelta.

La inevitable deducción que parece surgir del discurso visiral incide en la relación que se establece entre una nobleza a la cual representa Rejmira -la nobleza tebana-y la capacidad de un rey para sentarse en su trono, al parecer directamente proporcional a su generosidad con Tebas o a su habilidad para no enfrentarse a la oligarquía tebana.

El siguiente factor que valorar es el conflicto manifiesto entre las afirmaciones del visir, registradas profusamente en su enterramiento y las pautas de poder fijadas a parte del texto que nos ocupa. Es imposible conciliar las paredes de la tumba de Rejmira con la explicación que tradicionalmente viene dándose a Los Deberes del Visir y urgente avanzar en una interpretación rigurosa y crítica del mismo.

Si tomamos el texto e intentamos deducir cuánto hay en él de elemento ideal y cuánto de real, adivinaremos un horizonte de marcadas incoherencias que sin duda deben ser expuestas. Un primer ejemplo sería la Sección Tercera, de acuerdo a la obra de van den Boorn ${ }^{50}$, analizada por David Lorton ${ }^{51}$ en la cual se presenta una secuencia de hechos que implica la permanencia del visir y del rey en un mismo territorio:

R5: Now, he shall enter to greet the Lord L.H.P., each day when the affairs of the Two Lands have been reported to his in his residence. He shall enter the Great House when the overseer of the treasury $^{52}$ has drawn up his position at the northern flagstaff. Then the vizier shall move (in) from the East in the doorway of the great double-gate.

R6: The overseer of the treasury shall come to meet him and he shall report to him saying: "All your affairs are sound and prosperous. Every res-

47. Davies, 1943: 31

48. Davies, 1943: 31, nota a pie de página 70 .

49. Aparentemente contradictorios pues se trata de, al menos, los dos planos en los cuales se mueve habitualmente la documentación textual e iconográfica en la superestructura egipcia y por tanto sólo en un acercamiento superficial se aprecian discrepancia. El discurso oficial marcado por toda una serie de preconcepciones ideales a menudo es interpretado desde enfoques metodológicos tributarios de un simbolismo sin asidero real, como versiones de la práctica política absolutamente ajustadas a derecho, utilizando una terminología jurídica.

50. Lorton, 1991. En el presente artículo sigo la traducción, transliteración y segmentación de este autor.

51. Lorton, 1991: 292.

52. El rol de este cargo político en el protocolo de ceremonias rígidamente ordenadas puede verse con claridad en la TT50, donde aparece introduciendo al propietario y a dos gobernadores. 
ponsible functionary has reported to me saying:

'All your affairs are sound and prosperous; the palace is sound and prosperous"'.

Se informa al visir de los asuntos de Egipto en su propia casa, según las conclusiones extraídas de los pasajes anteriores y defendidas tanto por van der Boorn como por Lorton. Una vez puesto al día, se encaminaría hacia el palacio donde, en un espacio muy determinado, es recibido por otro alto cargo estatal -el imy-r jetem-considerado tesorero en la versión de Lorton y supervisor del tesoro en la de van den Boorn. Su función en este contexto tan reglado consiste, según se deduce del pasaje, en dar al visir las novedades que hubieran podido ocurrir en el per-nesu y en recibir las nuevas de la Residencia. No se trata de iniciar aquí una polémica sobre la interpretación que se ha realizado tanto de las categorías reservadas para el per nesu y residencia como del contexto en que ambas se ven envueltas, pero es indispensable exponer una serie de puntos que, de acuerdo al examen defendido en esta investigación, no han sido suficientemente valorados en el momento de realizar una lectura integra del pasaje.

El visir se acerca a la residencia oficial dentro de una ceremonia absolutamente protocolizada que aparenta ser difícil de cumplir cada día ya que el visir no reside en el mismo lugar que el rey como él mismo ha manifestado en su tumba, y por tanto la ceremonia en ningún momento puede formar parte de las obligaciones diarias inherentes al ejercicio del ministerio. Cabe destacar, una vez más, que los monarcas del Reino Nuevo fueron abandonando paulatinamente la capital para desplazarse al norte, pero que no sucedió lo mismo con la administración del estado que permaneció donde solía, bajo el amparo de Tebas y en su propio territorio y por esta circunstancia, que es subrayada manifiesta y repetidamente en la tumba, el texto debe ser tomado con precaución al menos en su literalidad. Aquí ya enfrentamos un primer problema: si tomamos el texto como normativo y lo adscribimos a la categoría de "administrativo" admitimos una territorialidad para la corona en franca contradicción con la documentación que manejamos, aunque -y aquí reside el elemento de irracionalidad- coherente con el discurrir del pensamiento egiptológico a este respecto. Partiendo de esa premisa no podría explicarse el documento en su conjunto ya que lejos de fluir por los cauces que cabría esperar de una audiencia real ${ }^{53}$ si avanzamos en la lectura del texto, descubriremos que las competencias del visir abarcan desde ocuparse de los mensajeros hasta seleccionar a la guardia que escolta al rey en sus desplazamientos, nombrar jefes de policía y escuchas, conceder barcos para expediciones, juzgar los asuntos internos de la institución..., y no soporta la hipótesis de van den Boorn respecto del control ejercido por el rey. Sin embargo expresa con nitidez la influencia del visir sobre todos aquellas cuestiones que juzgamos vitales en la dinámica del poder. El texto afirma que el visir es el máximo detentador del poder en cuestiones tan sensibles como la propiedad de la tierra, los tribunales de justicia, el nombramiento de esos mismos tribunales, los jueces etc., en suma, recae bajo su responsabilidad el peso del gobierno fiscalizando toda actividad legal, administrativa, interior y exterior pues también las asuntos de las fortalezas le incumben. Como colofón él decide cómo repartir el botín de guerra entre los territorios ${ }^{54}$ :

R26: It is to his that every legal matter has to be reported. It is to him that the affairs of the fortress of Upper Egypt have be reported (as well

53. Lo que, en la práctica, supone la historiografía tradicional que se está reflejando.

54. Este calificativo también puede ser entendido desde la idealidad y en ocasiones simplemente se refiere a los bienes recibidos como fruto del intercambio comercial o de tributos. 
as) every arrest of (any) one who is involved in plundering $[\ldots]$. It is he who assigns the spoils (of war) to each town district. It is he who judges him (the plunderer) ${ }^{55}$.

Debemos preguntarnos, si aceptamos la afirmación como válida, dónde queda la prerrogativa real, tan celebrada en cualquier estela que se precie, relativa a la adjudicación de botín.

Caben dos posibles soluciones al conflicto entre documentación real y nobiliaria, la primera es que los textos del visir exageran sus prerrogativas y su tarea se limitaba a cumplir instrucciones del rey; la segunda deriva del papel simbólico e idealizado inherente a toda documentación de la monarquía. Optando por esta variable, se llegaría a una conclusión radicalmente diferente. La monarquía entrega el botín de guerra (el rey lo hace formalmente), pero es la nobleza, representada por el visir, quien decide el reparto. El último análisis es coherente con la documentación que manejamos en el presente trabajo, atañe a las nuevas disposiciones para los tributos y también explica las razones de la permanencia del visirato en Tebas a pesar del extrañamiento monárquico.

Obviando las implicaciones que la pérdida del control sobre un elemento de cohesión tan poderoso supondría para la corona, el ejemplo es válido, una vez más, para entender la distancia que separa en Egipto la realidad discursiva de la acción de gobierno. Mientras la primera sigue manteniendo al faraón como sujeto de la decisión, la segunda se encarga de resolver la ecuación en el plano cotidiano y despoja al mo- narca de esa cualidad, transformándolo de actor en espectador ${ }^{56}$; la segunda plasmación del hecho político debe permanecer oculta y a ello se aprestan, como es de todos sabido, estructura institucional y superestructura ideológica, siendo ésta una de las razones que me indujo a tratar la dialéctica de la realeza desde el discurso (el plano ideal y de ocultación) y las medidas económicas (la materialización del poder).

Con todo, como anunciaba al inicio de este trabajo, estamos en el camino y únicamente tratamos de fijar una serie de principios rectores a partir de los cuales se desarrollará una investigación más extensa y compleja.

Concluyo mencionando someramente $L a$ Instalación del Visir, texto que añade, a las facultades del texto anterior, la instauración, en el seno de la misma familia, de una co-regencia visiral única, jamás explicada por los sectores más tradicionales de la Egiptología aunque absolutamente coherente por las razones que han ido apareciendo a lo largo de este trabajo y por la propia dinámica que la familia impuso, tanto en su relación con la realeza como en su ascensión a la cabeza de la elite dirigente del país, la nobleza tebana. Como el espacio es limitado simplemente avanzaré mi intención de tratarlo en trabajos posteriores como un texto que debe adscribirse al género de las Enseñanzas, nacido y desarrollado al amparo del clan que nos ocupa y que, en perfecta armonía con el otro gran vector ideológico de la época -la diosa Waset-, establece una contundente asimilación entre la obra de visir y el gran principio rector del buen gobierno: Maat

55. van den Boorn, 1988: 250.

56. Por supuesto puede objetarse que las órdenes vienen directamente del rey pero salvo en contadas ocasiones, que más bien parecen de puro compromiso, el texto alude a la figura del rey como suprema potestad y en cualquier caso ¿qué puede objetar al reparto un monarca de 10 años como es el caso de Amenhotep III y sus espléndidos regalos a Tebas? 


\section{Bibliografía}

Adams, W.Y.

1984 Nubia, corridor to Africa. London.

Barsanti, A.; Gauthier, H.

1911 Stèles trouvées à Ouadi Es-Saboua (Nubie), ASAE XI: 64-84.

Bogoslovsky, E.S.

1981 On the System of the Ancient Egyptian Society of the epoch of the New Kingdom According to documents from Deir el-Medina, $A O F$ 8: 5-21.

BOORN, VAN DER, G.P.F.

1982 On the Date of 'The Duties of the Vizier', OR 51: 369-381.

1988 The Duties of the Vizier. Civil Administration in the Early New Kingdom. London.

BOTHMER, V.

1968 Private Sculpture of Dynasty XVIII in Brooklyn, BMA 8: 55-89.

DAIRAINES, S.

1933 L'Egypte économique sous la XVIIIe dynastie pharaonique ou un socialisme d'État quinze siècles avant J.C. Paris.

Davies, N. DE; Davies, N. DE

1943 The Tomb of Rekh-Mi-Rea at Thebes. New York.

Dewachter, M.

1984 Les "premiers fils royaux d'Amon" compléments et remarques, $R d E$ 35: 83-94.

Dziobek, E.

1993 Some King's Sons Revisited, GM 132: 29-32.

1994 Theban Tombs as a Source for Historical and Biographical Evaluation: The Case of User-Amun, SAK 12: 129-142.
FAULKNER, R.O.

1955 The Installation of the vizier, JEA 41: 1829.

GARDINER, A.H.

1904 The Installation of a vizier. Rec. Trav. XXVI: 1-19.

Gauthier, H.

1917 Fils Royaux de Kouch" et le personnel administratif de L'Ethiopie, Rec. Trav. XXXIX: 179-238.

GRIFFITHS, J. GwYN

1953 The Egyptian Derivation of the Name Moses, JNES 12, 4: 225-231.

HABACHI, L.

1957a The Graffiti and work of the Viceroys of Kush in the Region of Aswan, Kush V: 13-36.

1957b Two Graffiti at Sehel from the Reign of Queen Hatshepsut, JNES 16, 2: 88-104.

1959 The First Two Viceroys of Kush and their Family, Kush VII: 4-63.

1984 The Family of The Vizier Ibic and his place among The Viziers of the Thirteenth Dynasty, SAK 11: 113-126.

HoRnung, E.

1961 Die Grabkammer des Vezirs User. Göttingen.

1965 Zur Familie des User, Z̈̈S 92: 75-76.

LOPRIENO, A.

1998 Nhsj “Der Südländer”?, en H. Guksch und D. Polz (eds.): Stationen Beiträge zur Kulturgeschichte Ägyptens, Mainz: 211217.

LORTON, D.

1991 What was the pr-nsw and who managed it?, $S A K$ 18: 291-316. 
Meulenaere, H. DE

1966 Deux viziers de Ramsès II, $C d E$ LXI: 223232.

RANKE, $\mathrm{H}$.

1935 Die Ägyptischen Personennamen. New York.

REISNER, G.A.

1920 The Viceroys of Ethiopia, JEA VI: 28-55.

SAUNeron, S.

1968 La Statue d'Ahmosé, dit Rourou au Musée de Brooklyn, Kémi XVIII: 45-56.

SÄVE-SÖDERBERGH, T.

1956 The Nubian Kingdom of the Second Intermediate Period, Kush IV: 54-61.

SCHNEIDER, T.

1992 Asiatische Personennamen in ägyptischen Quellen des Neuen Reiches. (OBO 114). Friburg/Göttingen.

SIMPSON, W.K.

1972a Egyptian Statuary of Courtiers in Dynasty 18, $B M B$ LXX: 36-49. 1972b Ah-mose, called Pa-tjenna, $B M B$ LXX: 116-117.

1979 Egyptian Sculpture and Two-Dimensional Representations as Propaganda, JEA 68: 266-272.

1996 Belles Lettres and Propaganda in Ancient Egyptian Texts, en Loprieno, A. (ed.): Ancient Egyptian Literature. History and Forms, Leiden: 435-443.

UPHILL, E.P.

1975 The office $s \underline{d} 3 w t y$-bity, JEA 61: 250.

VANDERSLEyen, C.

1971 Les Guerres D'Amosis Fondateur de la XVIIIe Dynastie. Bruxelles.

Vernus, P.

1982 La stèle du roi Sekhemsankhtaouyrê Neferhotep Iykhernofert et la domination Hyksôs (Stèle Caire JE 59635), ASAE LXVIII: 129-136.

Wilbour, E.C.

1890 Canalizing the Cataract, Rec. Trav. XIII: 202-203. 


\section{Trabajos de Egiptología Papers on Ancient Egypt}

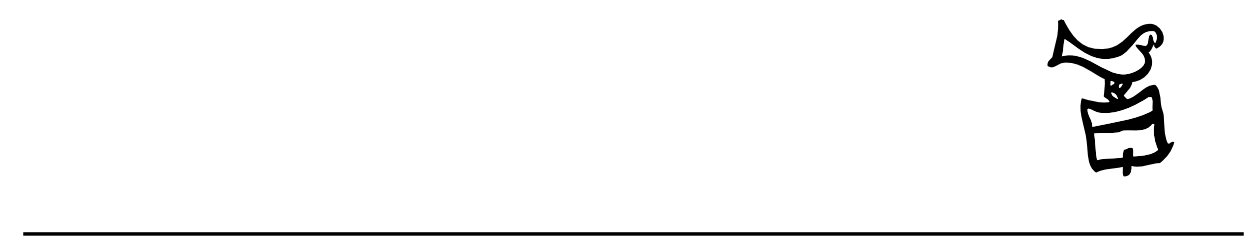

Número 5/1 2009 


\section{Actas \\ III Congreso Ibérico de Egiptología III Congresso Ibérico de Egiptologia}

Editores

Miguel Ángel Molinero Polo Covadonga Sevilla Cueva 


\title{
Editor
}

Miguel Ángel Molinero Polo

Universidad de La Laguna

\section{Consejo Editorial}

\author{
Antonio Pérez Largacha \\ Universidad de Castilla-La Mancha \\ José-R. Pérez-Accino \\ Birkbeck, Universidad de Londres \\ Covadonga Sevilla Cueva \\ Universidad Autónoma de Madrid
}

\section{Comité Científico}

Josep Cervelló i Autuori

Universitat Autònoma de Barcelona

$\mathrm{M}^{\mathrm{a}}$ José lópez Grande

Universidad Autónoma de Madrid

Josep Padró i Parcerisa

Universitat de Barcelona

$\mathrm{M}^{\mathrm{a}}$ Carmen Pérez Die

Museo Arqueológico Nacional, Madrid

Ester Pons Mellado

Museo Arqueológico Nacional, Madrid

José M. Serrano Delgado

Universidad de Sevilla

\section{Colaboradores Editoriales}

Linda Steynor

English editorial assistant

Hervé Mouriacoux

Assistant éditorial pour la langue française 
Trabajos de Egiptología está producida por Isfet. Egiptología e Historia c/ Blanco $1,2^{\circ}$

38400 Puerto de la Cruz

Tenerife-Islas Canarias

España

Maquetación: Proyecto Limón

(C) Autores de los artículos aparecidos

y Consejo Editorial de Trabajos de Egiptología - Papers on ancient Egypt

Depósito Legal: TF-2302-2009

ISSN: $1695-4750$

Imprime: Gráfica Los Majuelos, S.L.L.

imprenta@graficaslosmajuelos.com

Tfno.: 922311455 


\section{Comité Científico \\ III Congreso Ibérico de Egiptología III Congresso Ibérico de Egiptologia}

Miguel Á. Molinero Polo

Universidad de La Laguna

Presidente del Comité Organizador del III Congreso Ibérico de Egiptología

Miembro del Comité Organizador del I Encuentro de Egiptología

Josep Cervelló Autuori

Universitat Autònoma de Barcelona

Presidente del Comité Organizador del II Congreso Ibérico de Egiptologia

José Manuel Galán Allué

Consejo Superior de Investigaciones Cientificas

Director del Proyecto Djehuty, Luxor, Egipto

$\mathrm{M}^{\mathrm{a}}$ Helena Trindade Lopes

Universidad de Lisboa

Directora de la Misión Arqueológica Portuguesa en Menfis

Josep Padró i Parcerisa

Universitat de Barcelona

Director de la Misión Arqueológica de Oxirrinco

Antonio Pérez Largacha

Universidad de Castilla - La Mancha

Miembro del Comité Organizador del I Encuentro de Egiptología

José Ramón Pérez-Accino

Birkbeck College, University of London

Miembro del Comité Organizador del I Encuentro de Egiptología

$\mathrm{M}^{\mathrm{a}}$. Carmen Pérez Díe

Museo Arqueológico Nacional

Directora de la Misión Arqueológica Española en Heracleópolis Magna, Egipto

Covadonga Sevilla Cueva

Universidad Autónoma de Madrid

Miembro del Comité Organizador del I Encuentro de Egiptología 